\title{
Apothecaries Scruple
}

National Cancer Institute

\section{Source}

National Cancer Institute. Apothecaries Scruple. NCI Thesaurus. Code C64563.

The non-SI unit of mass equal to 20 grains or 1.2959782 grams. 